\title{
An active treatment of lung adenocarcinoma cancer with brain metastases: icotinib
}

This article was published in the following Dove Press journal:

OncoTargets and Therapy

8 June 2015

Number of times this article has been viewed

\author{
Ying Zhang \\ Huaping Tang \\ Jun Li \\ Meng Li
}

Department of Respiration Medicine, Municipal Hospital, Qingdao, People's Republic of China
Correspondence: Ying Zhang 5 Donghai Middle Road, Qingdao, Shandong, People's Republic of China Tel +86 I3589200795 Email zhangyoufang163@163.com

\begin{abstract}
Lung cancer has the highest mortality rate of all cancers worldwide. A total of $70 \%-75 \%$ of all lung cancers are non-small cell lung cancer (NSCLC) with two-thirds presenting with locally advanced or metastatic disease at diagnosis. Brain metastasis is one of the most common problems in the management of NSCLC, worsening the prognosis and quality of life of NSCLC patients. The epidermal growth factor receptor tyrosine kinase inhibitors (EGFR-TKIs) gefitinib and erlotinib have been tested in patients with NSCLC and brain metastasis. Icotinib is a new type of oral EGFR-TKI. In this report, we describe a patient with lung adenocarcinoma cancer with brain metastases who received icotinib treatment and kept satisfactory health-related quality of life for 1 year.
\end{abstract}

Keywords: EGFR, non-small cell lung cancer, tyrosine kinase inhibitor

\section{Introduction}

Brain metastases occur in $20 \%-40 \%$ of patients with advanced malignancies and lung cancer is one of the most common causes of brain metastases, especially in adenocarcinoma. ${ }^{1}$

The occurrence of brain metastases is associated with poor prognosis and high morbidity in patients with advanced lung cancer, even after intensive multimodal therapy. ${ }^{2}$ Traditionally, whole-brain radiation therapy (WBRT) has been the standard treatment for brain metastases with multiple intracranial lesions; in some cases, surgical resection, stereotactic radiosurgery, or some combination of the three can be used. ${ }^{3-6}$ The epidermal growth factor receptor (EGFR)-tyrosine kinase inhibitors (TKIs) gefitinib and erlotinib have been tested in patients with non-small cell lung cancer (NSCLC) and brain metastasis. Similar to primary tumors, the response of brain metastasis to EGFR-TKIs is better in patients with activating EGFR mutations, while the activity of these drugs in individuals with wild-type EGFR metastatic disease is very modest. ${ }^{7-9}$ In this report, we describe a patient with lung adenocarcinoma cancer with brain metastases who received icotinib treatment, which is a new EGFR-TKI, and who maintained satisfactory health-related quality of life for 1 year.

\section{Case report}

A 64-year-old female never-smoker was referred to our hospital due to presenting initially with cough, sputum, and chest congestion continuing for over 1 month on November 11, 2013. Computed tomography (CT) of the chest revealed an abnormal mass shadow in her left lung near the left hilum. A biopsy specimen obtained by fiber-optic bronchofiberscopy confirmed that the histology of the pathological change was adenocarcinoma of the lung (Figure 1). The serum concentration of the serum carcinoembryonic antigen was $53.32 \mathrm{ng} / \mathrm{mL}$. Magnetic resonance imaging demonstrated gadolinium-enhanced multiple nodules in the brain (Figure 2). Abdominal 


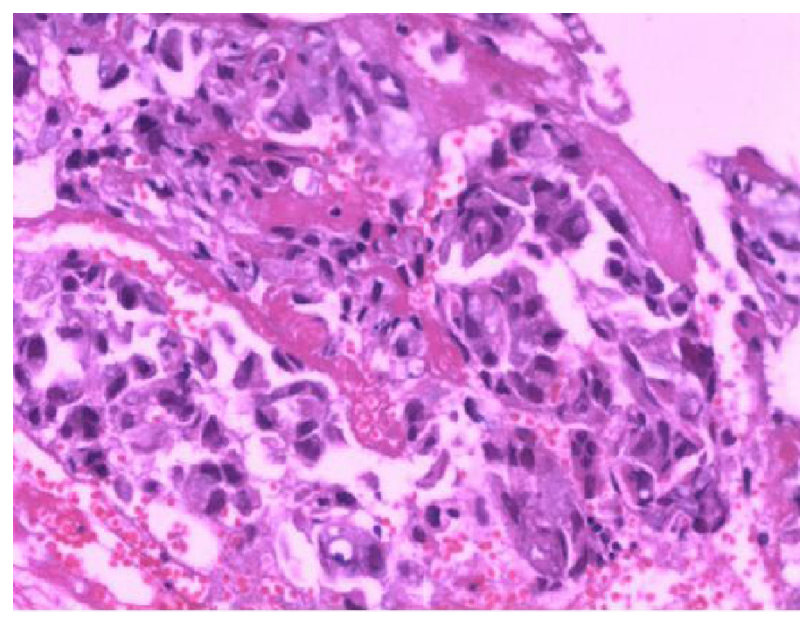

Figure I Hematoxylin-eosin-stained $(10 \times 20)$ biopsy specimens obtained by bronchofiberscopy.

Note: The tumor cells are large with highly atypical nuclei, and the histology and immunohistochemical findings suggest adenocarcinoma.

B-mode ultrasonography (the patient refused CT too often) and whole-body bone emission CT did not reveal any other distant metastasis. The patient was diagnosed as having adenocarcinoma of the lung with multiple brain metastases. According to the International Association for the Study of Lung Cancer version 7 NSCLC tumor-node-metastasis (TNM) clinical staging standard, the patient was T2N1M1 stage. No neural symptoms were observed and her Eastern Cooperative Oncology Group performance status (ECOG PS) was 0 at presentation; she not only looked after herself in her daily life, but cared for the diet of her husband. The patient refused brain irradiation and chemotherapy. Then, the EGFR mutation status was investigated and the result showed a point mutation at exon 21 (L858R).

She received icotinib (patent number WO2003082830; Zhejiang Bata Pharma Ltd., Hangzhou, People's Republic of China) after the result was EGFR mutation-positive. Icotinib $(125 \mathrm{mg})$ was orally administered three times per day. The adverse events - including grade 1 rash, grade 1 dry skin, and grade 1 diarrhea that occurred during the icotinib treatment - disappeared after 4 months. The patient had a very satisfactory quality of life, just as she had before, for almost half a year until she suffered from headache and nausea in September 2014. Imaging of the brain was not performed during icotinib therapy.

She visited our hospital on November 13, 2014 and complained of a little headache. This time the serum concentration of carcinoembryonic antigen was $17.85 \mathrm{ng} / \mathrm{mL}$, CT of the chest revealed the abnormal mass shadow in her left lung partial response, there was no new focus in whole lung. Abdominal B-mode ultrasonography and whole-body bone
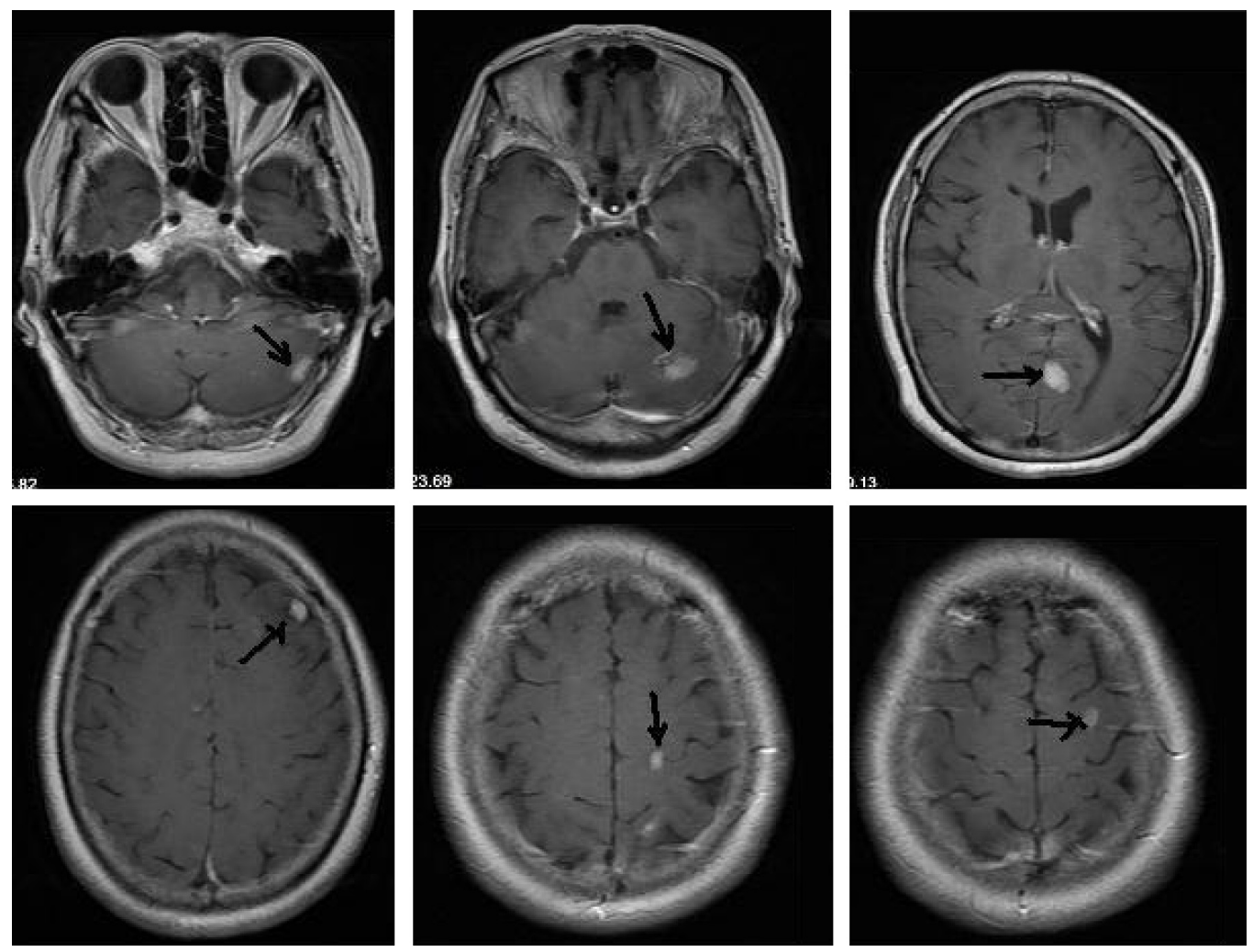

Figure $2 \mathrm{MRI}$ images.

Notes: MRI post-gadolinium enhancement shows marked enhancement of multiple metastases at different sizes in the left cerebellar hemisphere, left parietal lobe, bilateral occipital lobe, and frontal lobe. The maximum cross-section is about $1.8 \times 1.2 \mathrm{~cm}$. 

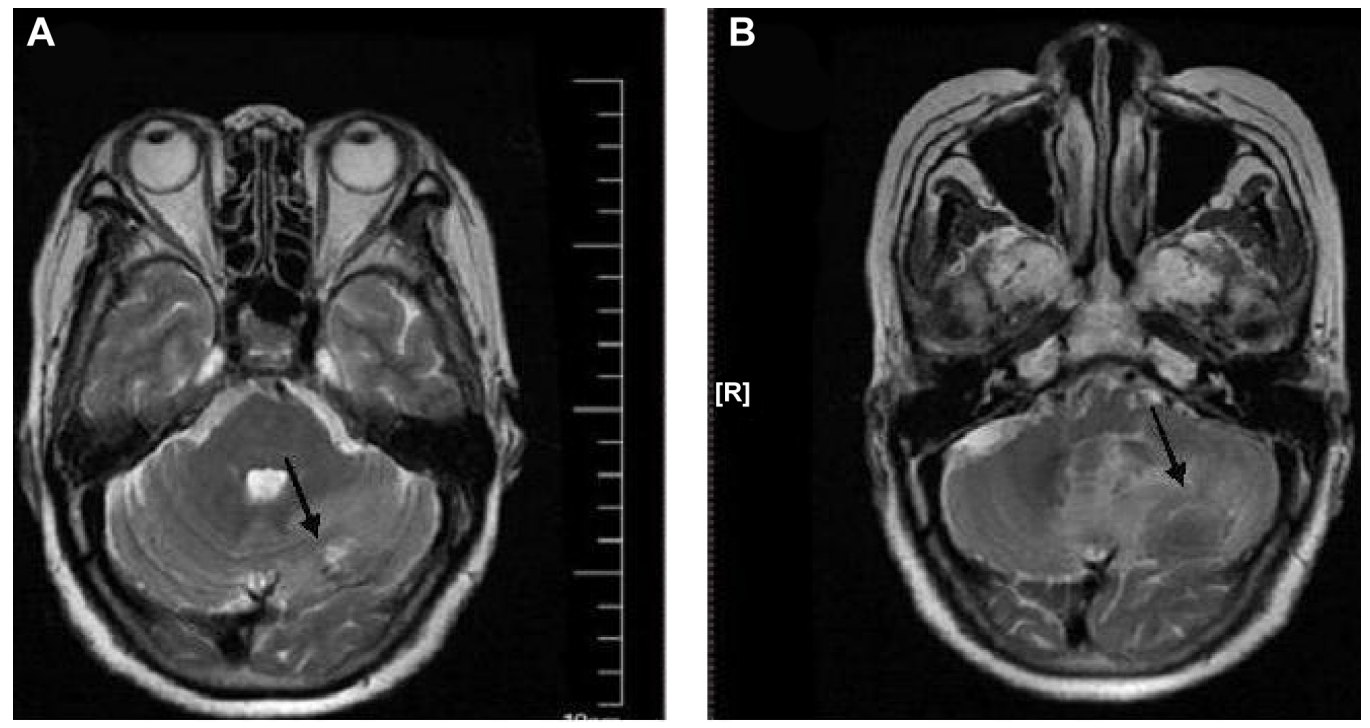

Figure 3 Brain MRI.

Notes: (A) Was taken on November 16, 2013. (B) Was taken on November 16, 20I4. MRI pre-gadolinium of brain showed there was no significant change in all the areas except for progressive lesions in the left cerebellar hemisphere (black arrow).

emission CT still did not reveal any other distant metastasis. Magnetic resonance imaging pre-gadolinium of brain showed there was no significant change in all areas except progressive lesions in the left cerebellar hemisphere (Figure 3). We used corticosteroids to alleviate her symptoms. The patient refused brain irradiation and chemotherapy or other EGFRTKIs, and was discharged on November 25, 2014 because of the sudden brain stroke of her husband at home. The patient was still alive as of April 3, 2015, she had taken icotinib for 15 months, and her ECOG PS was 1 at the time.

\section{Discussion}

Lung cancer patients develop brain metastases early, within the first 2 years, after primary tumor diagnosis. ${ }^{10}$ The median survival of NSCLC patients with brain metastases is 7 months. ${ }^{11}$ Age of the patient, performance status, number of brain metastases, and the presence of extracranial metastases are the variables that better define prognosis.

The management of brain metastases can be divided into symptomatic and therapeutic strategies which may include surgical resection, radiation therapy, or systemic therapy. Surgery for stage IV NSCLC involving an isolated brain has been recommended as a treatment option if mediastinal lymph nodes are not involved. ${ }^{12}$ There is, in particular, insufficient evidence to make a recommendation for patients with multiple brain metastases. Radiation therapy is still the mainstay of therapeutic strategies. ${ }^{10}$ WBRT is the most frequently used treatment for the management of brain metastases and its use is associated with improvement in neurologic symptoms and decreased neurologic death. ${ }^{13}$ Langley et al's study in 2013, which is the largest randomized trial to date looking at the role of WBRT in NSCLC, showed no overall survival benefit and no improvement in quality of life..$^{14}$ At the same time, Chang et al showed in 2009 that WBRT can negatively impact quality of life. ${ }^{15}$ Stereotactic radiosurgery delivers a single high dose of irradiation to the target volume while avoiding the surrounding normal tissues. Yamamoto et al's results suggest that stereotactic radiosurgery without WBRT in patients with five to ten brain metastases is noninferior to that in patients with two to four brain metastases. Considering the minimal invasiveness of stereotactic radiosurgery and the fewer side-effects than with WBRT, stereotactic radiosurgery might be a suitable alternative for patients with up to ten brain metastases ${ }^{16}$ However, these aggressive local therapies are not without risks. Chemotherapy has a limited role in the treatment of brain metastases: because it is assumed that most chemotherapeutic agents cannot cross the blood-brain barrier, the efficacy of these drugs in controlling NSCLC-related brain metastases remains controversial. ${ }^{17}$

EGFR-TKIs are now recognized as a standard first-line therapy, replacing conventional cytotoxic chemotherapy for patients with activating EGFR mutations, in response to randomized studies that demonstrated significantly higher overall response rates and longer progression-free survival. ${ }^{18-21}$ Zhao et al's research suggests that icotinib can effectively reduce the incidence of brain metastasis and therefore improve prognosis in advanced lung adenocarcinoma patients with EGFR-sensitive mutation. ${ }^{22}$ We agree that brain metastasis from lung cancer is a complex multistage and multistep pathological process, with significantly different pathological and clinical prognosis from other metastases, 
and the mechanism of brain metastasis is still under investigation. There are no data for us regarding cerebrospinal fluid penetration of icotinib, but our findings support the hypothesis that icotinib is able to cross the blood-brain barrier and displays efficacy against intracranial metastasis.

In our report, the patient and her family were adamant that what they wanted most of all was quality of life, not just pain living with the side-effects of the treatment, and they could not afford too much expensive medicine. They selected icotinib, and during the past 1 year icotinib had an effect and met their need. As a small-molecule inhibitor of EGFR-TKI, icotinib is not only an attractive treatment option for patients with lung adenocarcinoma cancer with brain metastases showing EGFR mutation-positive in the People's Republic of China, but also for people worldwide.

\section{Disclosure}

The authors report no conflicts of interest in this work.

\section{References}

1. Yawn BP, Wollan PC, Schroeder C, Gazzuola L, Mehta M. Temporal and gender-related trends in brain metastases from lung and breast cancer. Minn Med. 2003;86:32-37.

2. Hanibuchi M, Kim SJ, Fidler IJ, Nishioka Y. The molecular biology of lung cancer brain metastasis: an overview of current comprehensions and future perspectives. J Med Invest. 2014;61(3-4):241-253.

3. Tsao MN, Rades D, Wirth A, et al. Radiotherapeutic and surgical management for newly diagnosed brain metastases(es): An American Society for Radiation Oncology evidence-based guideline. Pract Radiat Oncol. 2012;2:210-225.

4. Kocher M, Soffietti R, Abacioglu U, et al. Adjuvant whole-brain radiotherapy versus observation after radiosurgery or surgical resection of one to three cerebral metastases: results of the EORTC 22952-26001 study. J Clin Oncol. 2011;29:134-141.

5. Patchell RA, Tibbs PA, Walsh JW, et al. A randomized trial of surgery in the treatment of single metastases to the brain. N Engl J Med. 1990; 22(322):494-500.

6. Andrews DW, Scott CB, Sperduto PW, et al. Whole brain radiation therapy with or without stereotactic radiosurgery boost for patients with one to three brain metastases: phase III results of the RTOG 9508 randomised trial. Lancet. 2004;363:1665-1672.

7. Eichler AF, Kahle KT, Wang DL, et al. EGFR mutation status and survival after diagnosis of brain metastasis in nonsmall cell lung cancer. Neuro Oncol. 2010;12(11):1193-1199.

8. Jamal-Hanjani M, Spicer J. Epidermal growth factor receptor tyrosine kinase inhibitors in the treatment of epidermal growth factor receptormutant non-small cell lung cancer metastatic to the brain. Clin Cancer Res. 2012;18(4):938-944.

OncoTargets and Therapy

\section{Publish your work in this journal}

OncoTargets and Therapy is an international, peer-reviewed, open access journal focusing on the pathological basis of all cancers, potential targets for therapy and treatment protocols employed to improve the management of cancer patients. The journal also focuses on the impact of management programs and new therapeutic agents and protocols on

Submit your manuscript here: http://www.dovepress.com/oncotargets-and-therapy-journal
9. Wu C, Li YL, Wang ZM, Li Z, Zhang TX, Wei Z. Gefitinib as palliative therapy for lung adenocarcinoma metastatic to the brain. Lung Cancer. 2007;57(3):359-364.

10. D'Antonio C, Passaro A, Gori B, et al. Bone and brain metastasis in lung cancer: recent advances in therapeutic strategies. Ther Adv Med Oncol. 2014;6(3):101-114.

11. Sperduto PW, Kased N, Roberge D, et al. Summary report on the graded prognostic assessment: an accurate and facile diagnosis-specific tool to estimate survival for patients with brain metastases. J Clin Oncol. 2012;30(4):419-425.

12. Shen KR, Meyers BF, Larner JM, Jones DR; American College of Chest Physicians. Special treatment issues in lung cancer: ACCP evidence-based clinical practice guidelines (2nd edition). Chest. 2007; 132(3 Suppl):290S-305S.

13. Khuntia D, Brown P, Li J, Mehta MP. Whole-brain radiotherapy in the management of brain metastasis. J Clin Oncol. 2006;24(8):1295-1304.

14. Langley RE, Stephens RJ, Nankivell M, et al. Interim data from the Medical Research Council QUARTZ Trial: does whole brain radiotherapy affect the survival and quality of life of patients with brain metastases from non-small cell lung cancer? Clin Oncol (R Coll Radiol). 2013; 25(3):e23-e30.

15. Chang EL, Wefel JS, Hess KR, Allen PK, et al. Neurocognition in patients with brain metastases treated with radiosurgery or radiosurgery plus whole-brain irradiation: a randomised controlled trial. Lancet Oncol. 2009;10(11):1037-1044.

16. Yamamoto M, Serizawa T, Shuto T, et al. Stereotactic radiosurgery for patients with multiple brain metastases (JLGK0901): a multiinstitutional prospective observational study. Lancet Oncol. 2014; 15(4):387-395.

17. Fan Y, Xu X, Xie C. EGFR-TKI therapy for patients with brain metastases from non-small-cell lung cancer: a pooled analysis of published data. Onco Targets Ther. 2014;7:2075-2084

18. Mitsudomi T, Morita S, Yatabe Y, et al. Gefitinib versus cisplatin plus docetaxel in patients with non-small-cell lung cancer harbouring mutations of the epidermal growth factor receptor (WJTOG3405): an open label, randomised phase 3 trial. Lancet Oncol. 2010;11(2):121-128.

19. Zhou C, Wu YL, Chen G, et al. Erlotinib versus chemotherapy as first-line treatment for patients with advanced EGFR mutation-positive non-smallcell lung cancer (OPTIMAL, CTONG-0802): a multicentre, open-label, randomised, phase 3 study. Lancet Oncol. 2011;12(8):735-742.

20. Rosell R, Carcereny E, Gervais R, et al. Erlotinib versus standard chemotherapy as first-line treatment for European patients with advanced EGFR mutation-positive non-small-cell lung cancer (EURTAC): a multicentre, open-label, randomized phase 3 trial. Lancet Oncol. 2012;13:239-246.

21. Wu YL, Zhou C, Hu CP, et al. Afatinib versus cisplatin plus gemcitabine for first-line treatment of Asian patients with advanced non-small-cell lung cancer harbouring EGFR mutations (LUX-Lung 6): an open-label, randomised phase 3 trial. Lancet Oncol. 2014;15(2):213-222.

22. Zhao X, Zhu G, Chen H, Yang P, Li F, Du N. Efficacy of icotinib versus traditional chemotherapy as first-line treatment for preventing brain metastasis from advanced lung adenocarcinoma in patients with epidermal growth factor receptor-sensitive mutation. J Cancer Res Ther. 2014;10 Suppl:C155-C159.

patient perspectives such as quality of life, adherence and satisfaction. The manuscript management system is completely online and includes a very quick and fair peer-review system, which is all easy to use. Visit http://www.dovepress.com/testimonials.php to read real quotes from published authors. 